\title{
Processing Government Documents
}

Miss $W$ ard is documents librarian, North Texas State College, Denton, Texas.

T April 1948, the Library of North 1 Texas State College was designated as a depository for United States government documents. Before that date all documents which had been acquired by purchase, exchange or gift were incorporated either in the regular Dewey classification with full cataloging, or in the pamphlet file by subject in the reference room. With the sudden arrival of documents by the hundreds, a longrange planning program became essential.

Several factors influenced the decision to organize a separate documents collection: (I) Shelving space. The already overcrowded stacks seemed an unwise location for a rapidly-growing new type of material. Temporary space was provided in the reference room, which was thought to be sufficient until such time as an addition to the building would provide permanent quarters. (2) Cataloging cost. Funds and personnel were not sufficient to give as complete cataloging to documents as to the other book material. It was also clear that this would be duplicating work in indexes published by the Government Printing Office. (3) Type of material. Small leaflets are difficult to keep in order under any circumstances, but in a special collection these elusive pieces can be given attention. (4) Personnel. In a separate collection the documents librarian has the advantage of having not only a general knowledge of the many different departments, bureaus, divisions, offices and independent agencies of the
Government, but also knows of transfers, mergers, new and discontinued titles, frequency, tricks in identifying obscure items and much additional miscellaneous information acquired only through working with documents. (5) Time element. With some exceptions, government documents are available for use almost immediately upon receipt if they are in a separate collection, since they can be put directly on the shelves.

The choice of a method of arrangement of documents within the collection was easy. The Documents Office classification is foolproof, as most of the pieces are given in the Monthly Catalog. The other usual method of arrangement, that of shelving the documents alphabetically by bureau and title, creates the problem of locating publications of bureaus which have changed from one department to another. In using the Documents Office classification this changing of bureaus need not necessarily affect the classification if sufficient cross references are made in the shelflist. An arbitrary rule of using the latest number was applied to those sets which had been transferred from one department to another. Cross references were made in the shelflist from each of the earlier classifications to the one used as follows:

I 6.43 :no. U.S. Office of education. Pamphlets.

see

FS5. 7 :no. U.S. Office of education. Pamphlets.

Any future change in classification will be represented by a cross reference to the old classification, which will be retained in 
order to avoid reclassifying, remarking, and reshelving of the set.

What should be done about the government periodicals? This question was answered by sending to the Periodicals Department all those periodicals which are indexed in one of the usual indexing tools. The other periodicals were given Documents classification numbers and retained in the documents collection, so that they could be shelved with other material on the same subject and prepared by the same office. For example, the C.A.A. Journal is classified

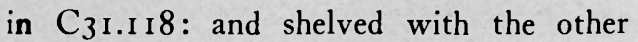
material published by the Civil Aeronautics Administration. Thus, a search for airplane hazards, latest improvements, accidents etc. will naturally lead to the Journal which might easily be missed if it were in another part of the library.

In setting up a system of record keeping, two separate files were started. One is merely an author list of holdings giving the classification number for each series as follows:

FRr.30:date U.S. Board of governors of the federal reserve system.

Federal reserve charts on bank credit, money rates, and business.

The only time spent on this file is in typing the card as each new series is added. No maintenance is required. The Poole list ${ }^{1}$ is an invaluable source of classification numbers needed in initiating the author file, and it is kept up to date by adding new classification numbers as listed each month in the front of the Monthly Catalog. It is possible to omit the author file and depend on the Poole list to provide the numbers each time a request is made for a document for which the classification is not known. However, this practice has two disadvan-

1 Poole, Mary Elizabeth. Documents Office Classifica. tion, Raleigh, N.C. The Compiler, North Carolina State College, I 945. tages. Titles under each bureau are not arranged alphabetically in Poole, and much time is spent in hunting the specific title desired in order to find the classification, particularly where the list of titles is a long one. Furthermore, after the desired title is finally located, very likely the publication has been transferred to another department, and the search must continue through the pages to run down the classification number that is eventually used.

The second file is a checklist of all publications arranged by classification number. Some libraries arrange this file by author and title in order to eliminate the author file entirely. However, with this system, no shelflist of documents is available and taking inventory would be extremely difficult. The documents librarian, working with a shelflist arrangement, can gain a clearer over-all view of the collection.

Checking cards are all locally printed as those available from library supply firms are not satisfactory for documents. Only three kinds of information are necessary on each checking card: author, title and classification number. Space at the top of commercial cards for publisher, source, frequency etc. is often needed for the extra two or three lines in the title. Four kinds of serial checking cards are used: number (I-IOO), annual (see Fig. I), monthly (also used for quarterly) and weekly. Other variations in frequency of publication may be adapted to the use of one of these printed cards.

Documents which do not fall within any series, i.e., pieces with a Cutter number, are listed on plain cards. The top of the card gives the same information as series cards (classification number, author and general title). Holdings are listed on the card alphabetically by Cutter number, giving title of piece and date of publication. (See Fig. 2.) 
CSI.3I :date U.S. Civil service commission.

Official register of the United States.

\begin{tabular}{c|c|c|c|c}
\hline \multicolumn{2}{|c|}{ LIBRARY HAS THOSE CHECKED..BELOW } & \multicolumn{2}{c}{ T1 } \\
\hline 1 & 11 & 21 & 31 & 42 \\
\hline 2. & 12 & 22 & 32 & 43 \\
\hline 3 & 13 & 23 & 33 & 44 \\
\hline 4 & 14 & 24 & 34 & 45 \\
\hline 5 & 15 & 25 & 35 & 46 \\
\hline 6 & 16 & 26 & 36 & 47 \\
\hline 7 & 17 & 27 & 38 & 48 \\
\hline 8 & 18 & 28 & 39 & 49 \\
\hline 10 & 19 & 29 & 40 & 50 \\
\hline
\end{tabular}

(Form 66)

FIG. I

(The full year is not printed so that the same form can be used for either 1801-1850 or 19011950. Only fifty years are put on one card in order to allow space for showing all the volumes and parts in which annual reports often appear.)

SI.2CT. U.S. Dept. of state.

General publications.

Ed83/2 Proposed educational and cultural organizations of the United $\mathrm{Na}$ tions. 1945 .

F 76p/12 Foreign policies; their formulation and enforcement. 1946.

P92 Presidential elections; provisions of the Constitution and the U.S. Code. 1948.

Fig. 2

(Space is left between Cutter letters to permit future publications to be listed in their alphabetical order.)

Inclusion of this type of document in the shelflist has many advantages over checking holdings in each Monthly Catalog. Classification numbers are often found in the Selected United States Government Publications and in the "Previews" in the Monthly Catalog, as well as on the piece itself if published by the Tariff Commission. Such numbers are available months before the piece is listed in its correct place in the Monthly Catalog. Thus, the document can be classified, added to the shelflist, shelved and ready for use without holding it up for checking off in a Monthly Catalog some months later. Likewise, many publications are merely revised editions requiring only a change in year designation (e.g., circulars of information regarding national parks) or added volumes having the same classification number except the volume number (e.g., hearings in several volumes). There is no need to spend the time necessary to look through many issues of the Monthly Catalog simply to check holdings and then to repeat the process to find a classification number every time a request comes for such a publication.

In using the collection to give reference service, all that is necessary is to check the shelflist to determine if a specific piece is in the collection. It is true that often the Monthly Catalog must be used to find the classification number of a particular document, but in many cases, as in the use of Price Lists and the Hirshberg Guide ${ }^{2}$ where

2 Hirshberg, Herbert S, and Melinat, Carl H. Subject Guide to United States Government Publications. Chicago, American Library Association, 1947. 
the classification is given, this search would be wasted effort. When information is needed that would obviously be published by a specific bureau, it should take only a moment to glance over the titles of publications listed in the shelflist and determine if any of them would be useful in the question at hand.

As an aid in calling attention to the documents collection, each series is represented in the public catalog by a card giving classification, author, title and the following note: "For complete holdings see Documents Collection." Each card also has a rubber stamp "Govt. doc." under the call number. (See Fig. 3)
SI.3I : U.S. Dept. of state.

GOVT. Near Eastern series. Washington,

DOC. Govt. print. office.

\section{FOR COMPLETE HOLDINGS SEE DOCUMENTS COLLECTION}

(FIg. 3)

(For separates, only those which seem important enough for cataloging are represented in the catalog by L.C. cards giving the Documents classification.)

In an effort to make the faculty documents conscious a selected list of current document acquisitions is included in the fortnightly publication N.T.S.C. Books which is sent to faculty members.

\section{Obstacles and Opportunities in Special Treatment of Documents}

\section{(Continued from page 47)}

ing by public libraries, as on-the-spot, or long-range through correspondence. The driving force in these campaigns was in the larger library a far seeing cataloger; in the smaller a determined trustee, herself an exlibrarian. If the pattern is once set and if some one member of the staff can become the foster mother of these problem children, documents, a small public library can make the depository privilege a help not a hinderance in serving their community.

The small college library has a tougher job. Its faculty members who frequently have done graduate work in a university or college with rich resources find a limited book stock maddening. When such a faculty member discovers his college library is a depository and can get endless stuff free, there may be a to-do. The care of material and what it involves is beyond his vision. We have tried to arbitrate in such cases.

Here then is an opportunity on a different level for a university or a state library to help documents and readers meet. At one time there seemed a chance to have such offthe-campus activities accepted as part of our university extension program. The project did not seem worthwhile to those in high places, and what has been done later has been on a person to person basis.

\section{Making Material Available in a National Crisis}

It is easy at times of national stress to become sentimental or emotional. With a sincere desire to avoid either of these attitudes, may I suggest one last opportunity for the special document worker or department? When a national emergency develops, all federal functions, activities and pronouncements become of increased importance. That the citizens may and must know the truth is mandatory. The public press, the radio and the library should assume in all seriousness this duty. Again this may be our part in a dangerous time. Two different young assistants on two different occasions made exactly the same remark to me. Suddenly in midst of tedious routine each said, "Is it not a privilege at a time like this to handle all this material from the Government?" Once this was said in the midst of a depression, once in the midst of war. If tragic times are ahead, may not document librarians rise to the opportunity of their positions and know it is a privilege? 